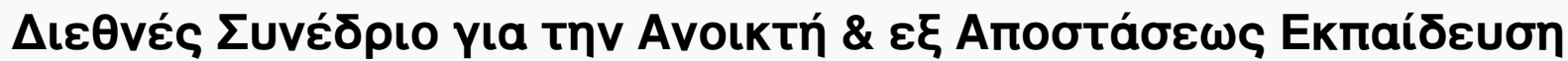

Tóp. 6, Ap. 2B (2011)

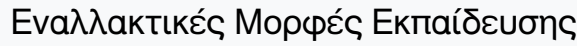

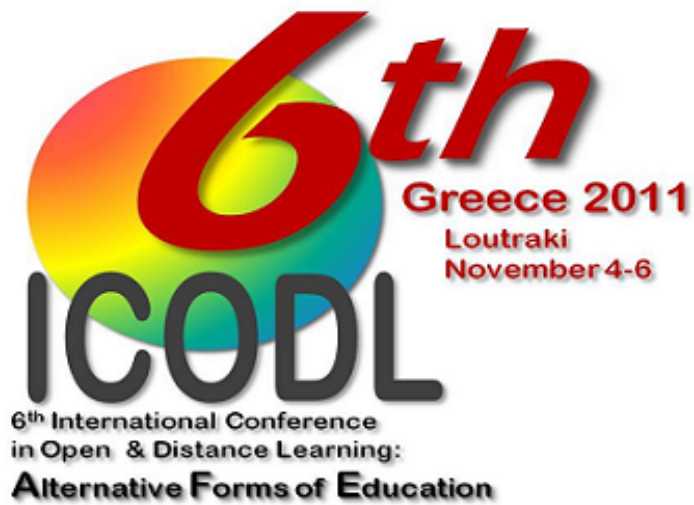

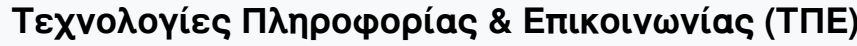

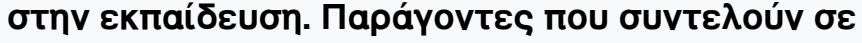

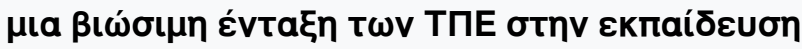

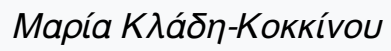

doi: $10.12681 /$ icodl. 674

TOMOE B

PART / MEPOE B 


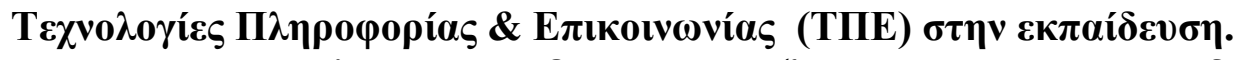

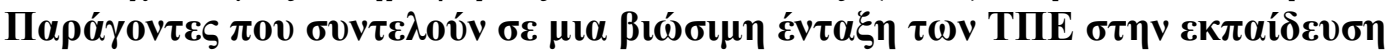

\title{
Information and Communication Technologies (ICT) in education. Factors which contribute to a sustainable use of ICT in education
}

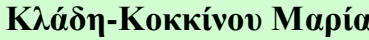

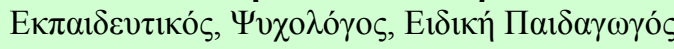

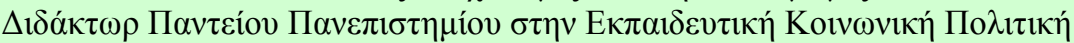 \\ kokkinoukladi@yahoo.gr
}

\begin{abstract}
.
This paper argues that meaningful access to ICT encompasses more than providing computers and internet connections. As many cases show problems arise when greater importance is given to physical availability of computers and to connectivity than the issues of content, language, education, literacy or community and social resources. There are three basic issues which are discussed here in relation to sustainable use of ICT in education. First the need for invasive education as opposed to letting students teach themselves the use of technology. Second the need for developing awareness, planning and setting up processes of sustainable change before the purchase of the equipment. Finally the need to plan social inclusion along with the introduction of ICT because although the lack of access to ICT harms chances of inclusion the reverse is equally true. Those who are already marginalized will have fewer opportunities to access and use of ICT. So while planning technology access programs apart from the physical resources (computers and telecommunication connections) they should also cater for digital resources (relevant content in diverse languages), human resources (literacy and education) and social resources (community, institutional and societal structures that support access to ICT).
\end{abstract}

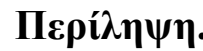

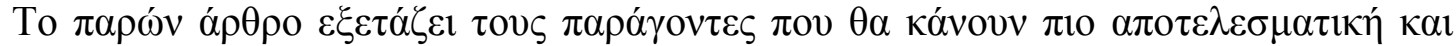

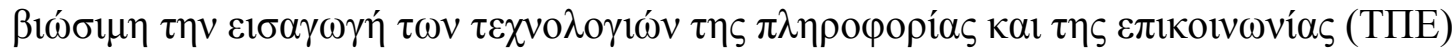

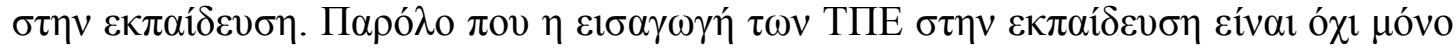

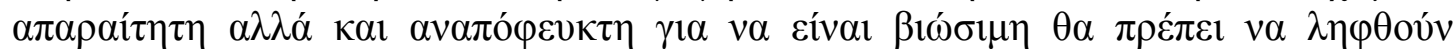

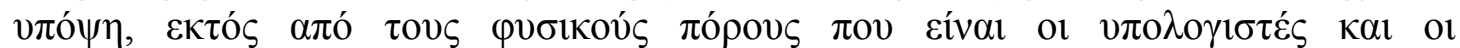

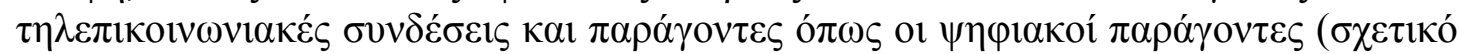

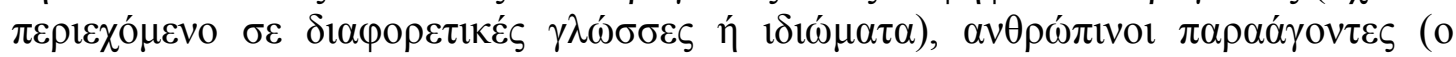

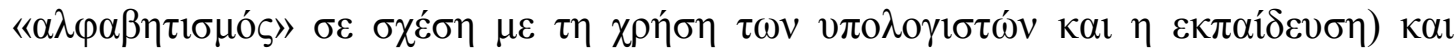

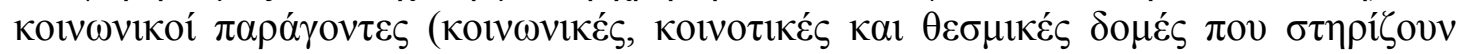

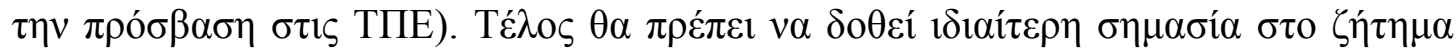

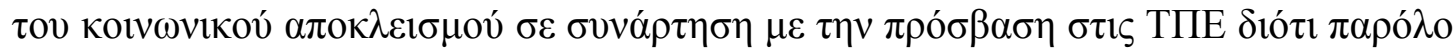

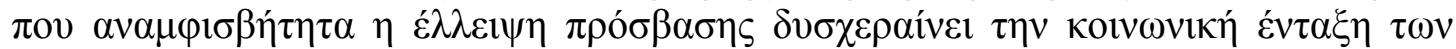

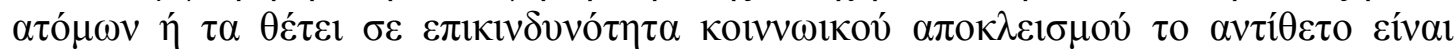

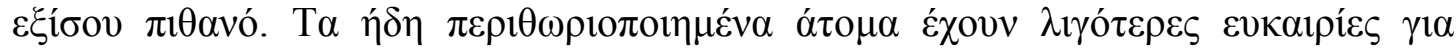

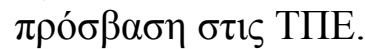




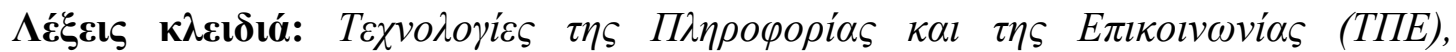

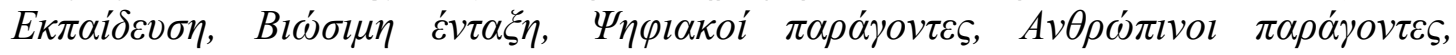

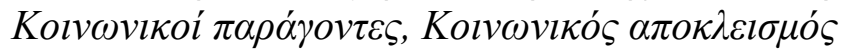

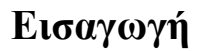

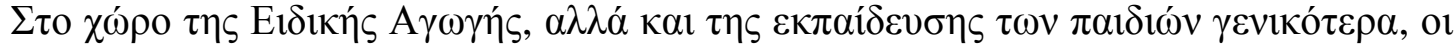

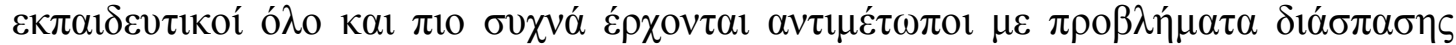

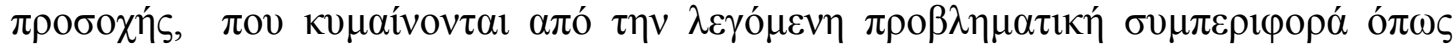

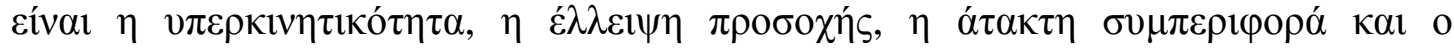

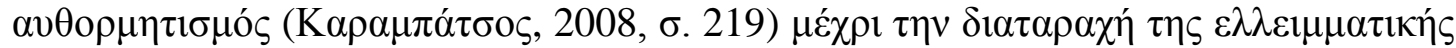

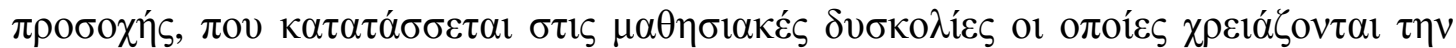

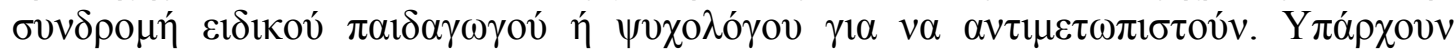

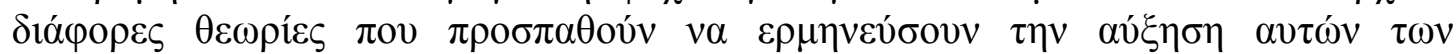

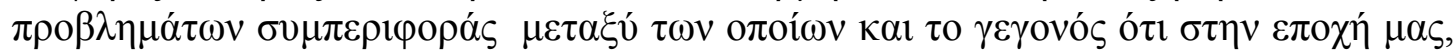

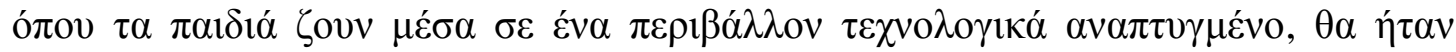

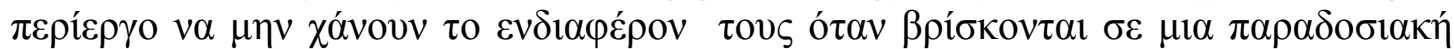

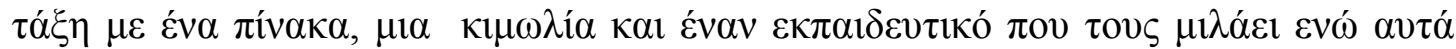

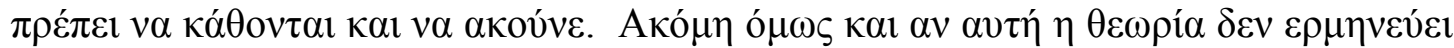

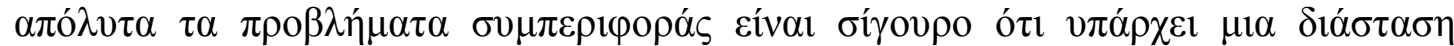

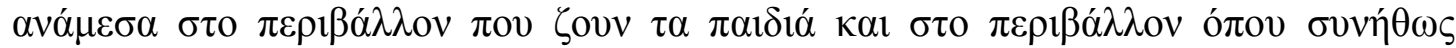

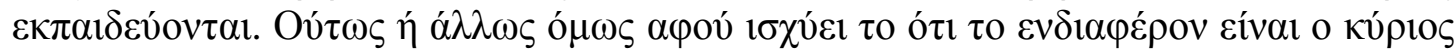

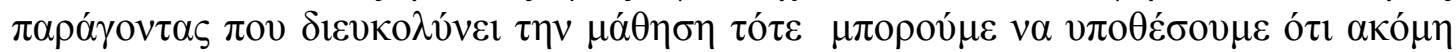

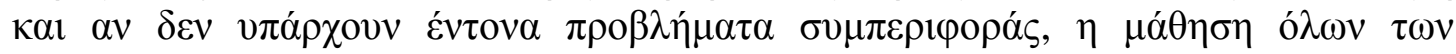

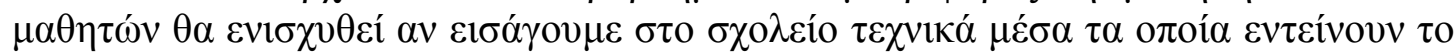

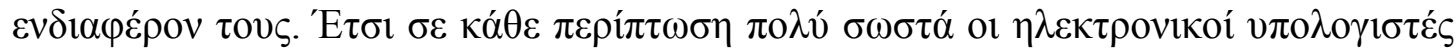

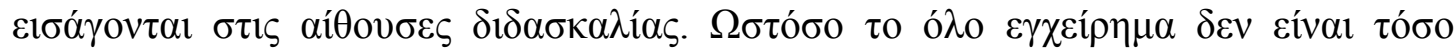

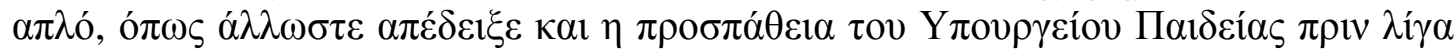

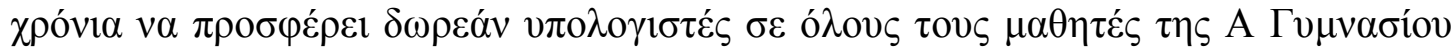

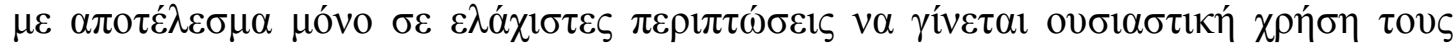

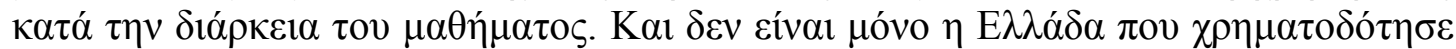

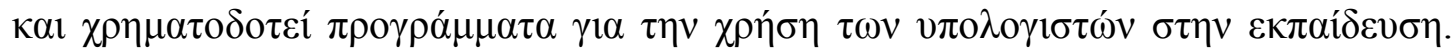

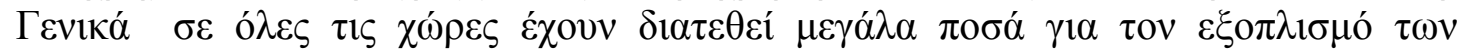

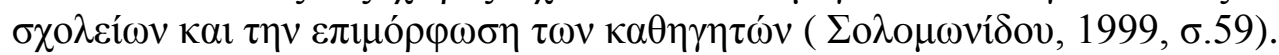

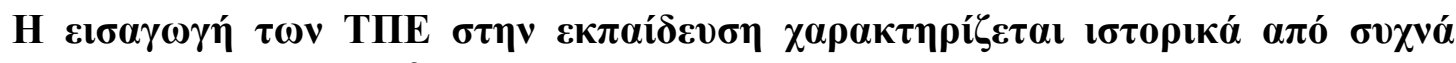 $\alpha \pi 0 \tau v \chi \eta \mu \varepsilon ́ v \varepsilon \varsigma \pi \rho 0 \sigma \pi \alpha ́ \theta \varepsilon เ \varepsilon \varsigma$}

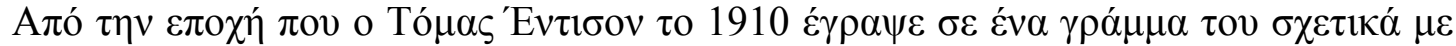

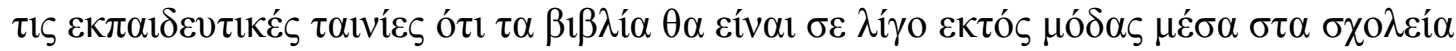

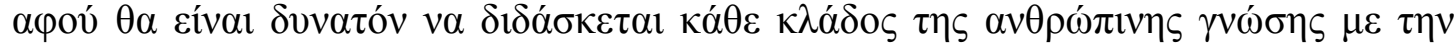

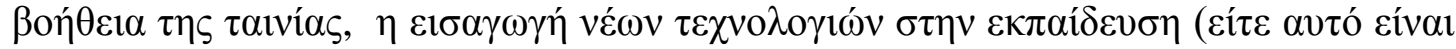

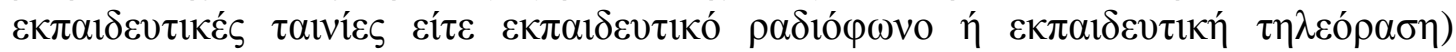

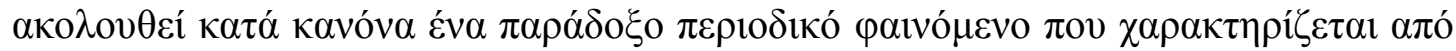

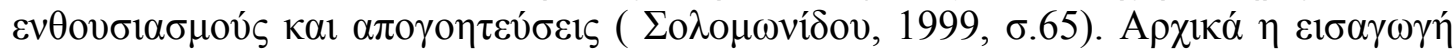

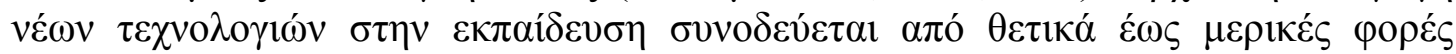

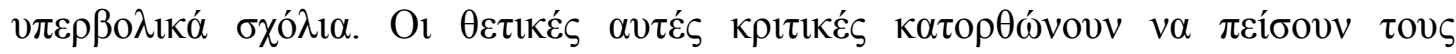

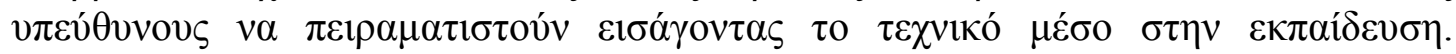

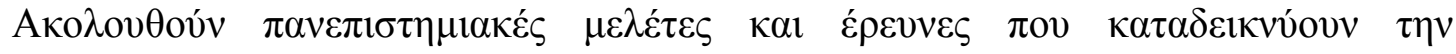

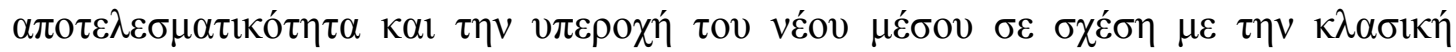

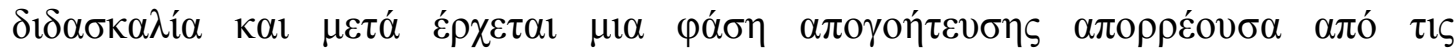

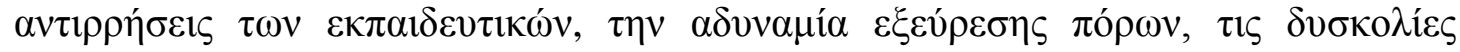




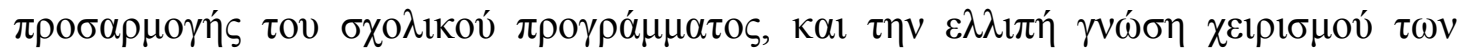

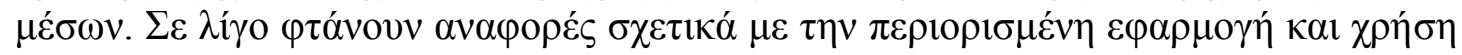

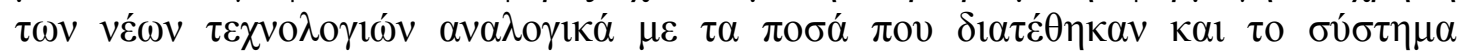

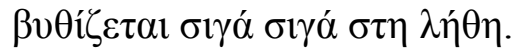

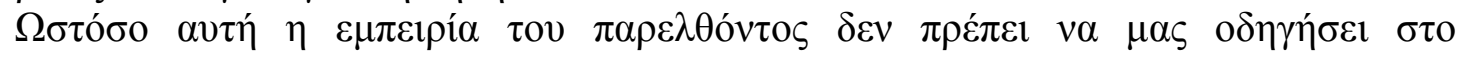

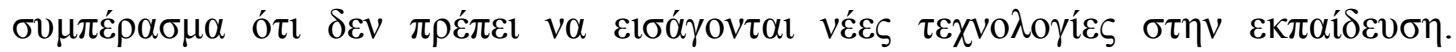

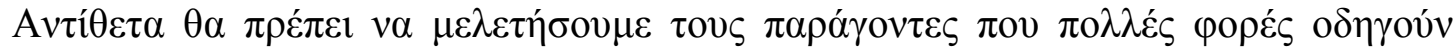

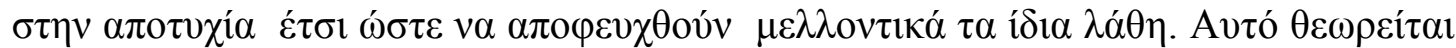

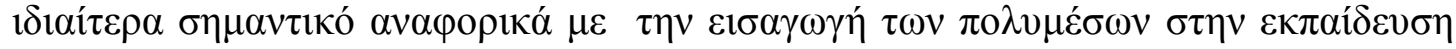

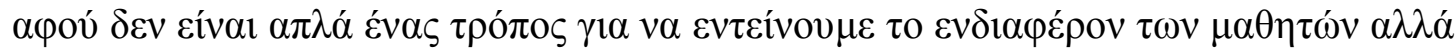

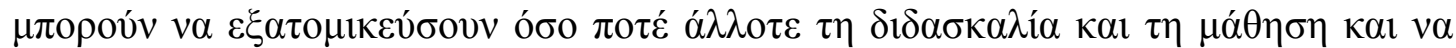

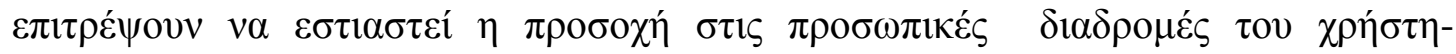

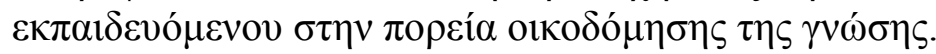

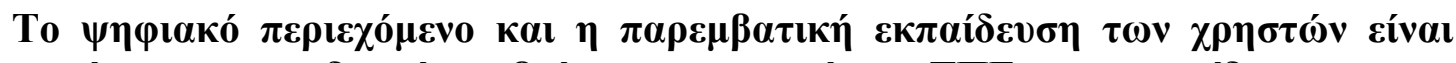

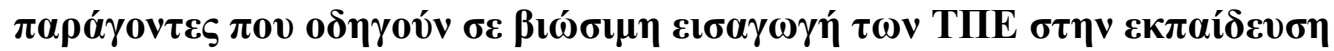

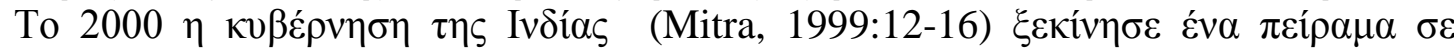

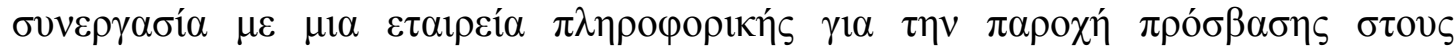

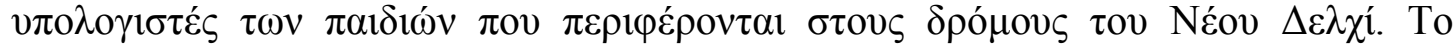

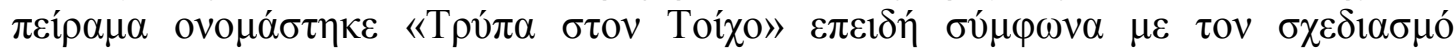

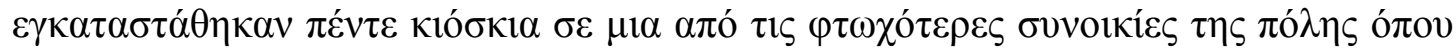

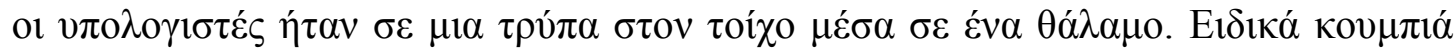

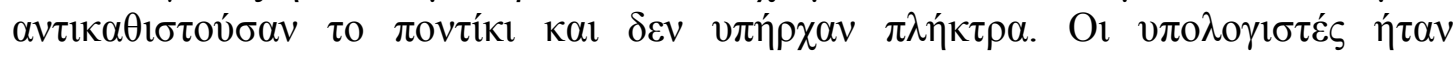

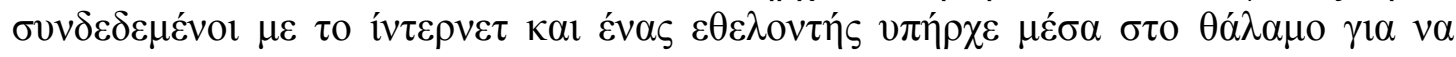

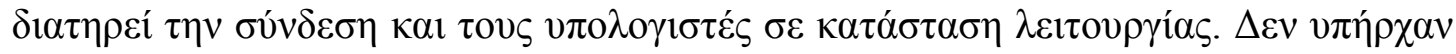

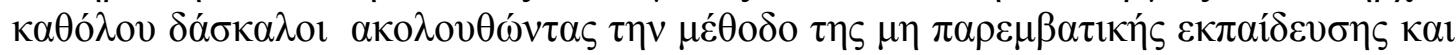

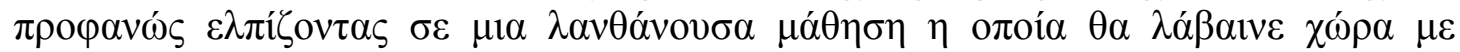

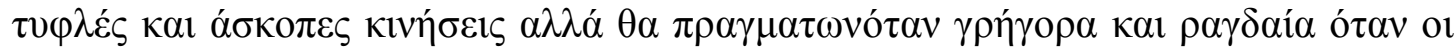

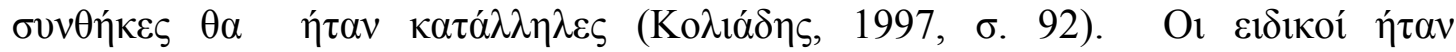

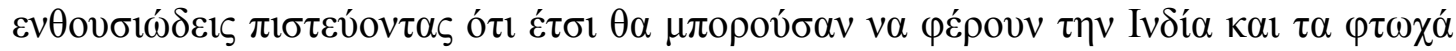

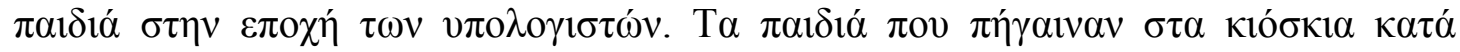

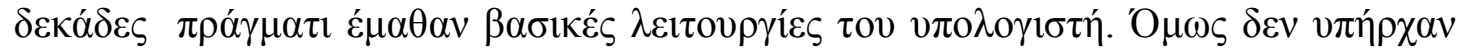

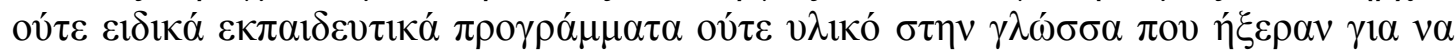

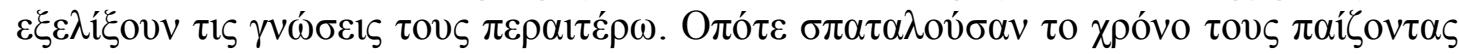

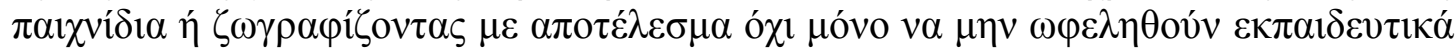

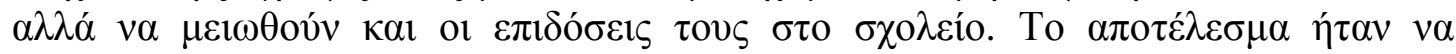

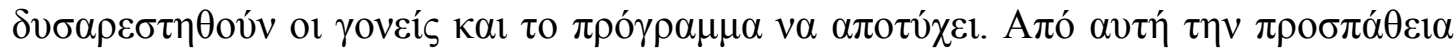

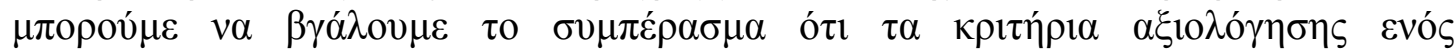

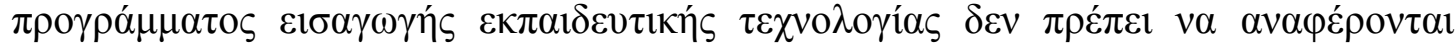

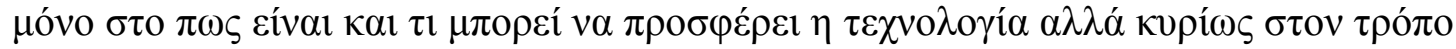

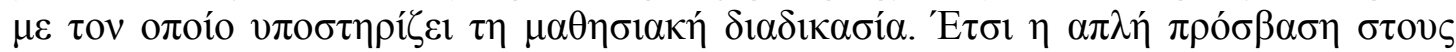

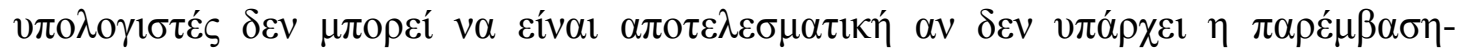

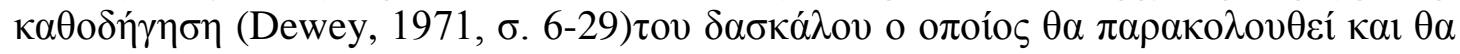

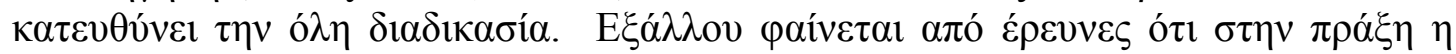

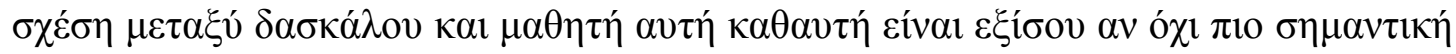

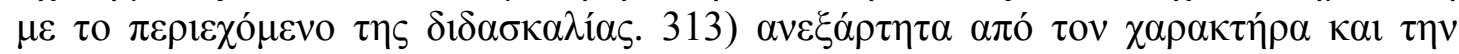

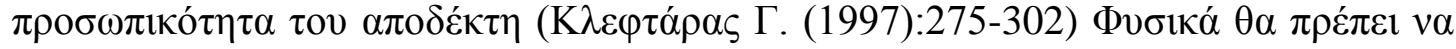

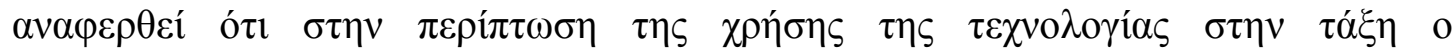

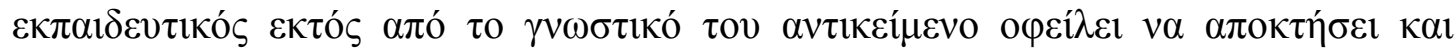

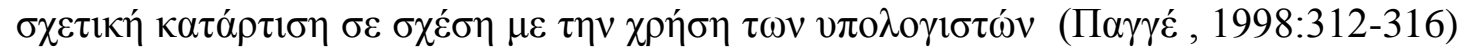




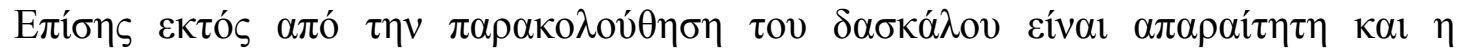

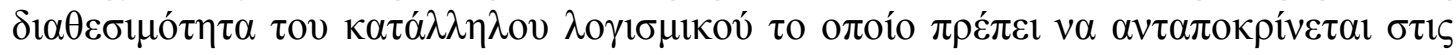

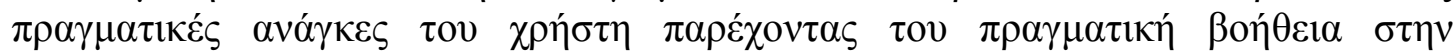

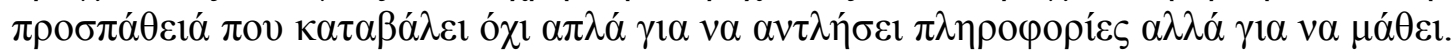

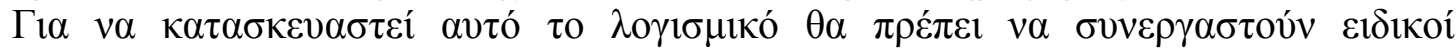

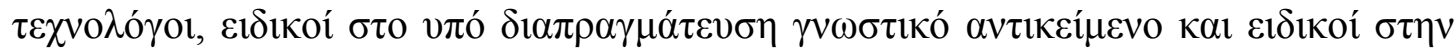

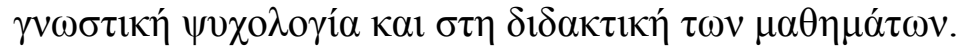

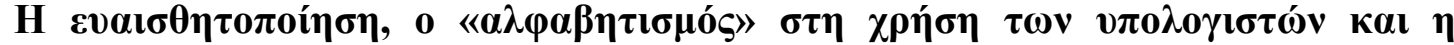

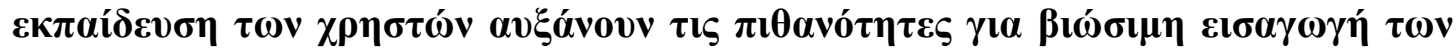

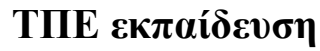

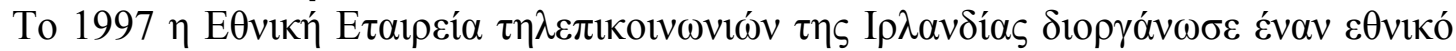

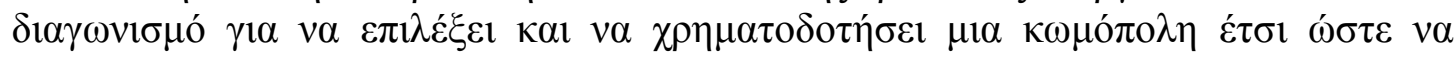

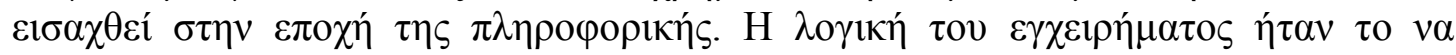

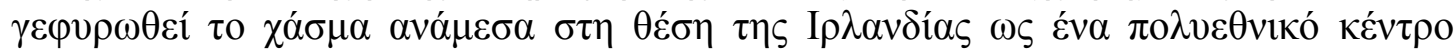

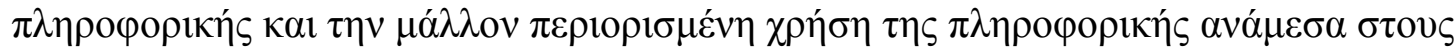

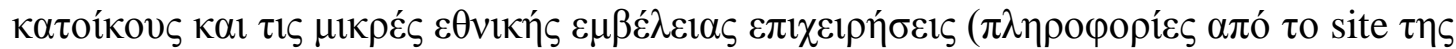
Eircom $\kappa \alpha$ l $\tau \alpha$ sites $\tau \omega v$ tó $\lambda \varepsilon \omega v$, http://www.eircom.ie, http://www.ennis.ie, http://www.castlebar.ie, http://www.kilkenny.ie, http://www.kerry.local.ie/killarney)

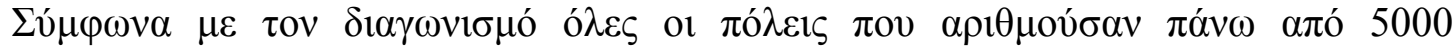

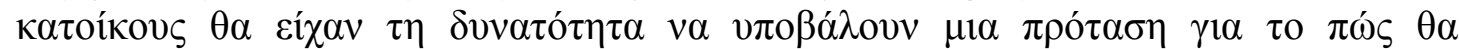

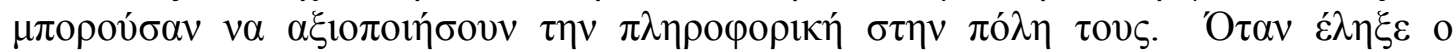

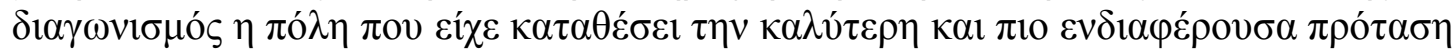

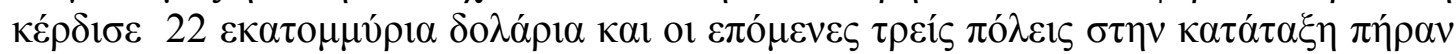

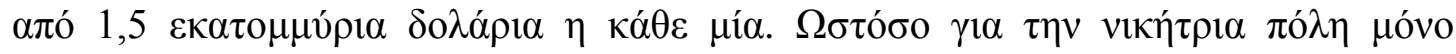

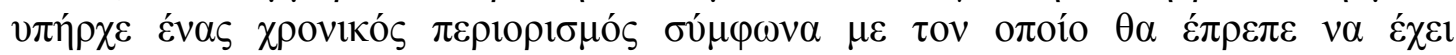

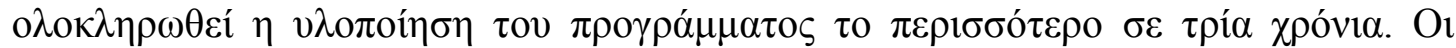

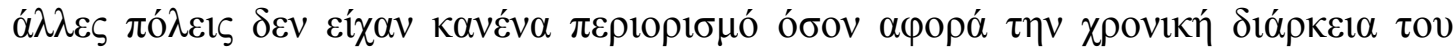

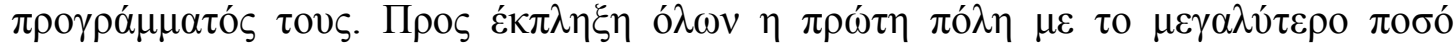

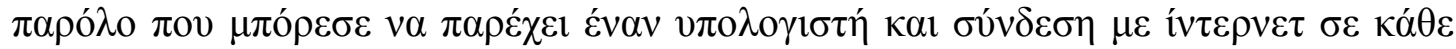

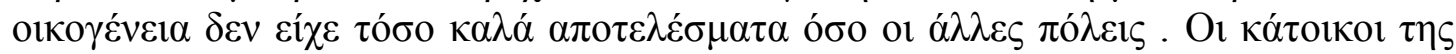

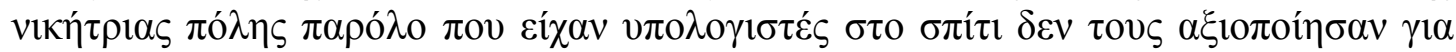

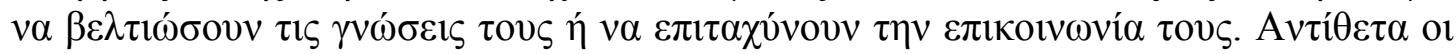

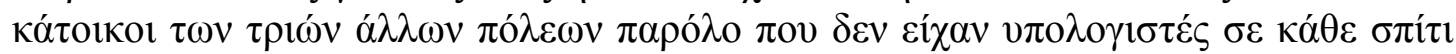

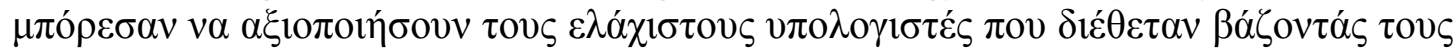

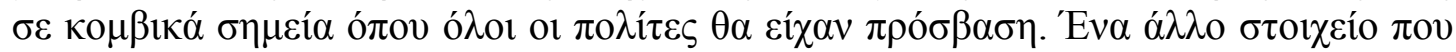

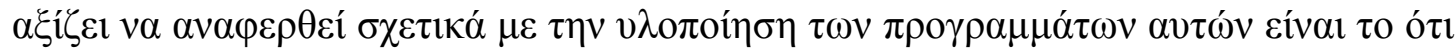

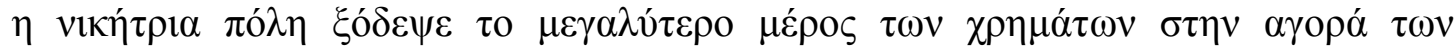

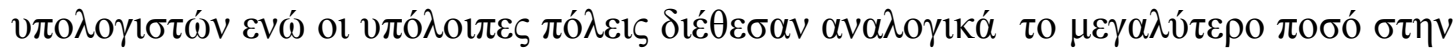

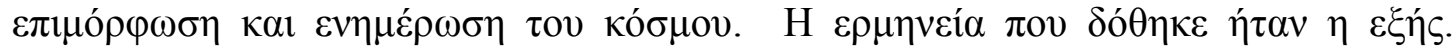

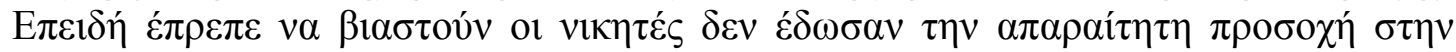

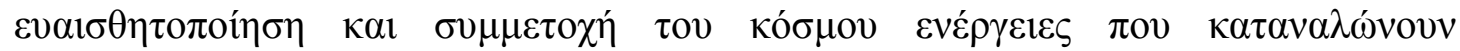

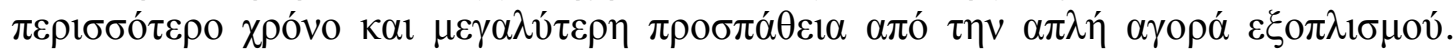

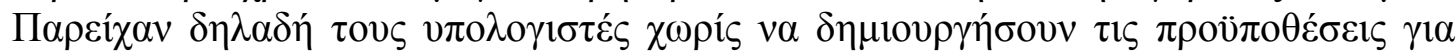

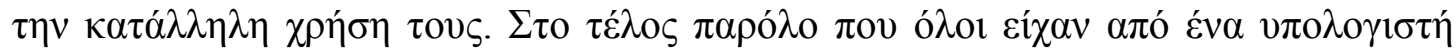

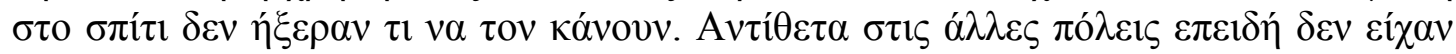

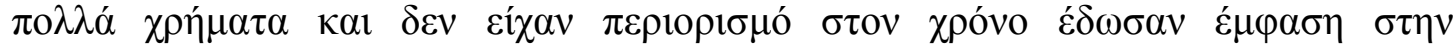

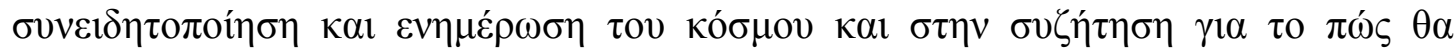

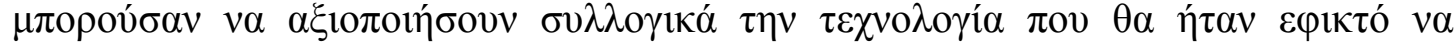

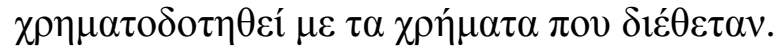




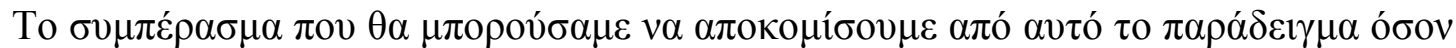

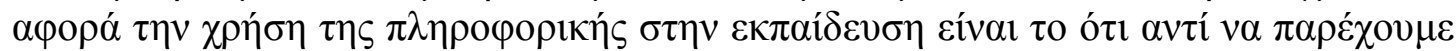

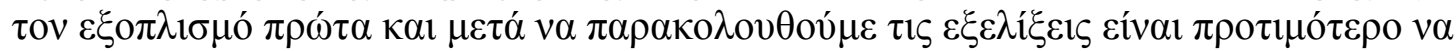

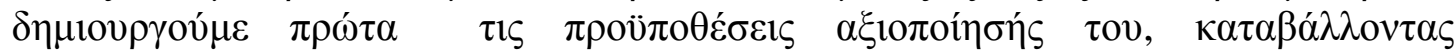

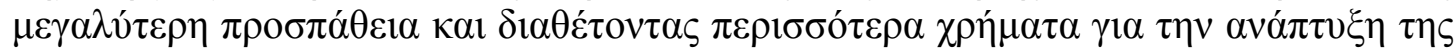

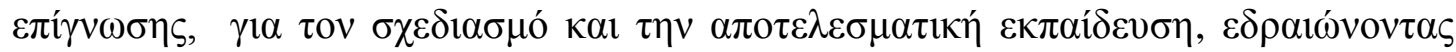

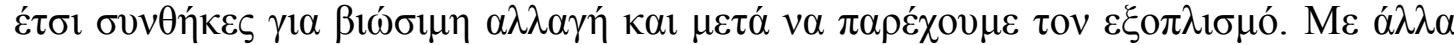

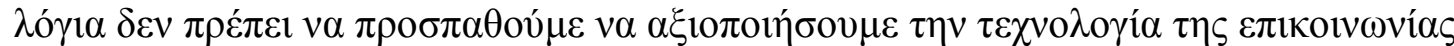

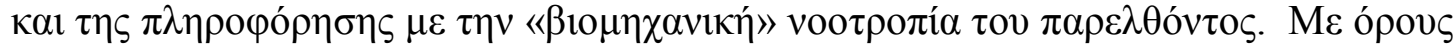

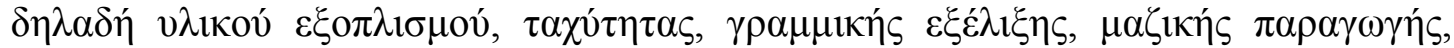

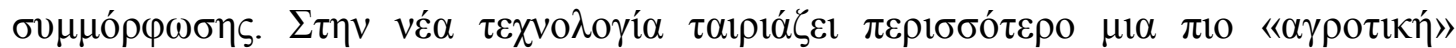

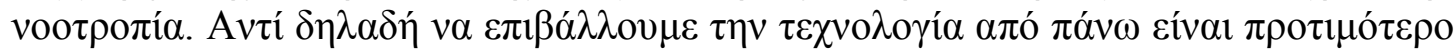

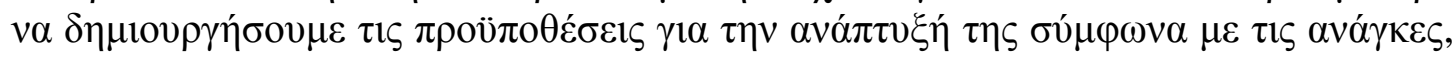

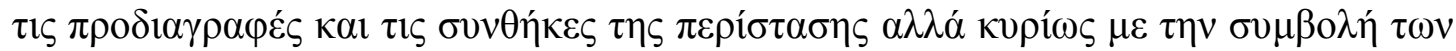

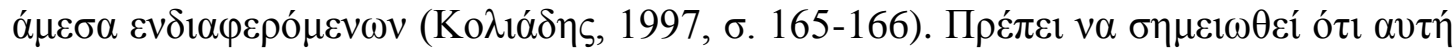

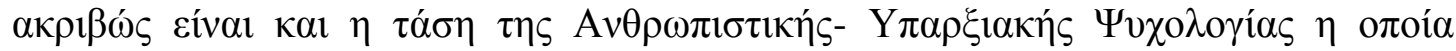

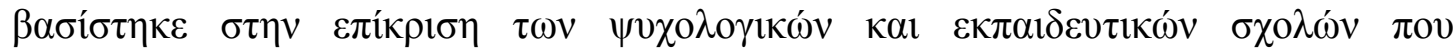

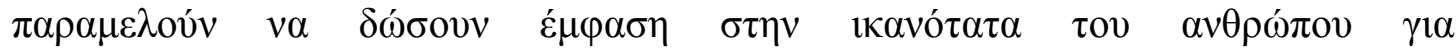

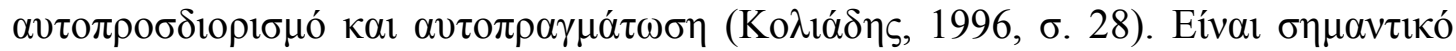

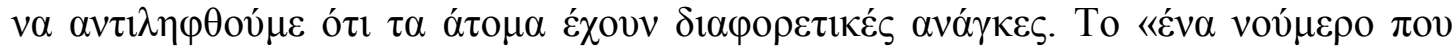

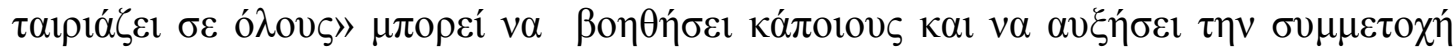

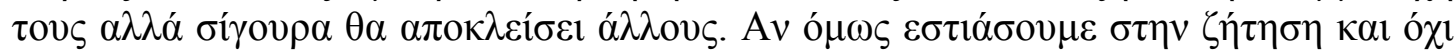

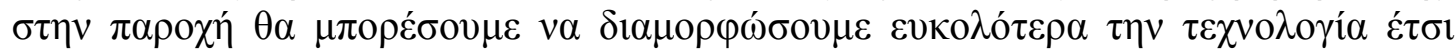

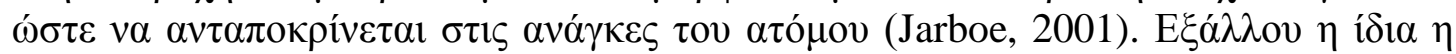

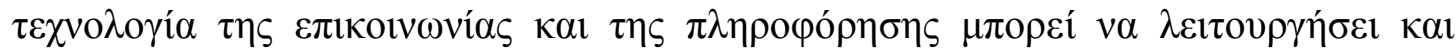

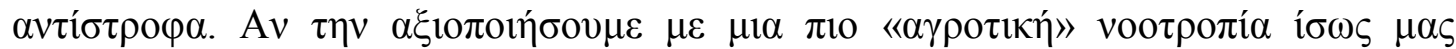

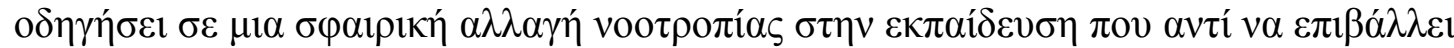

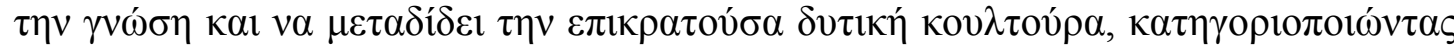

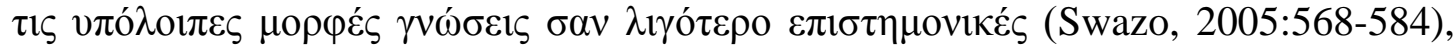

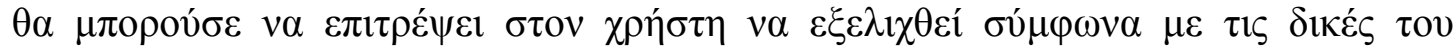

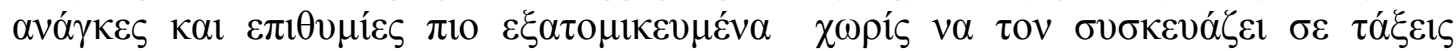

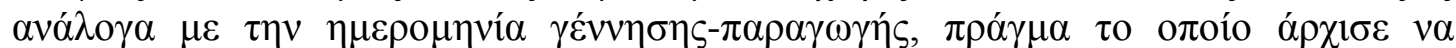

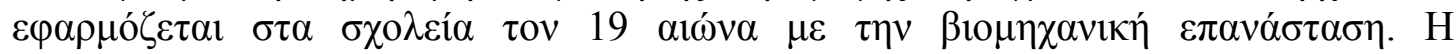

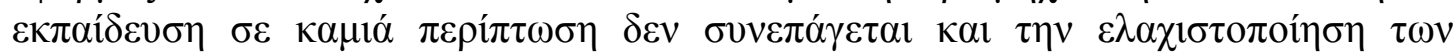

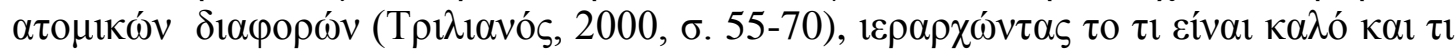

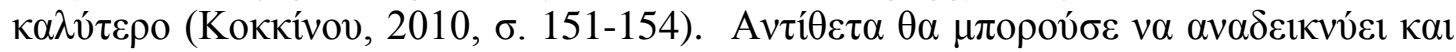

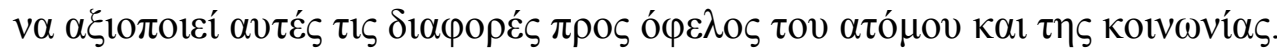

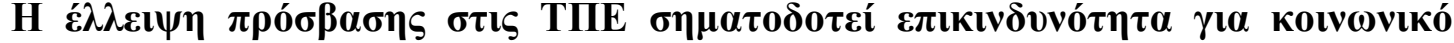

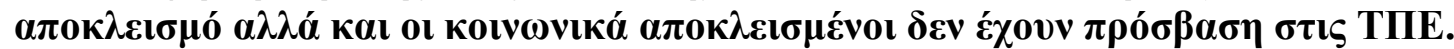

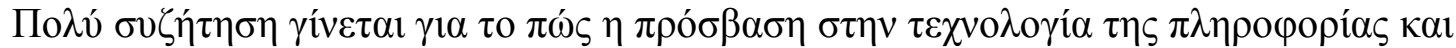

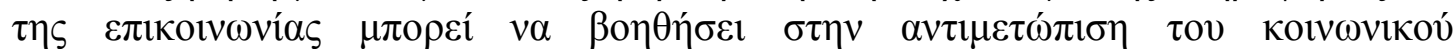

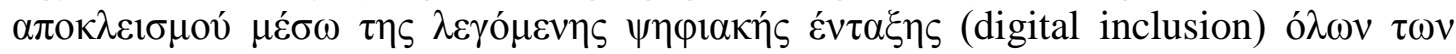

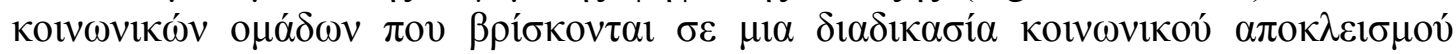

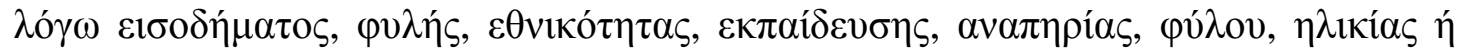

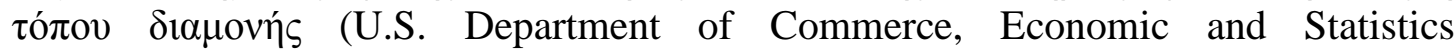
Administration, National Telecommunications and Information Administration,

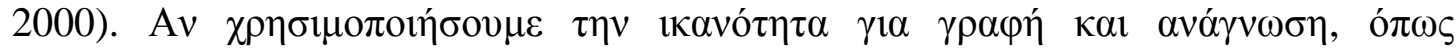

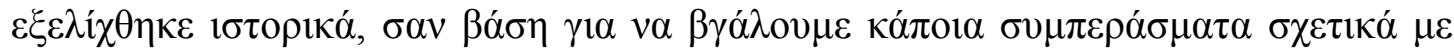

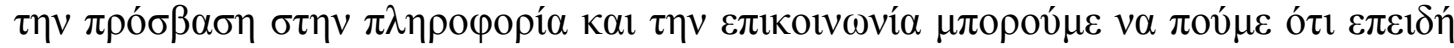




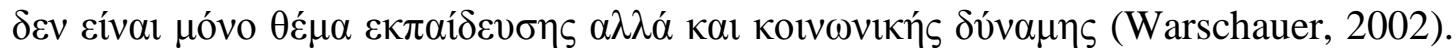

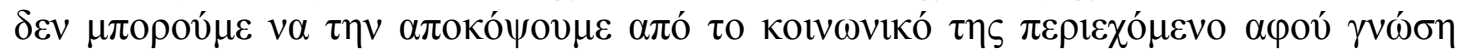

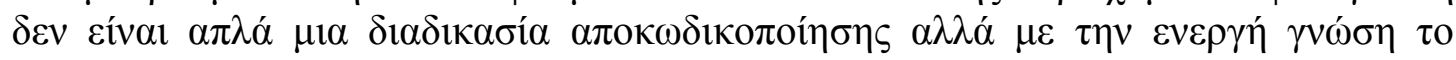

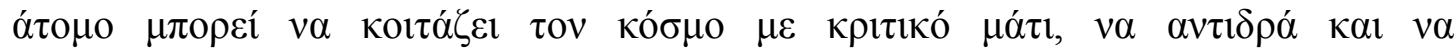

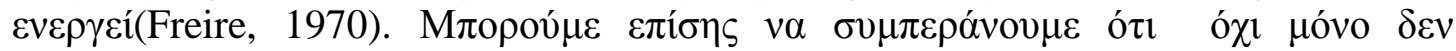

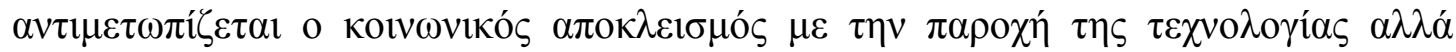

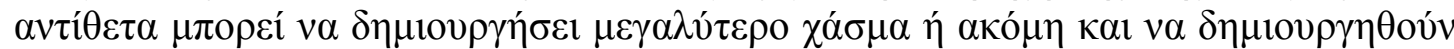

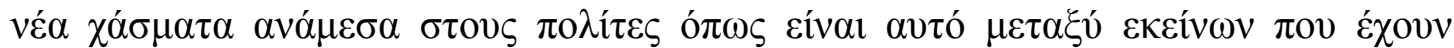

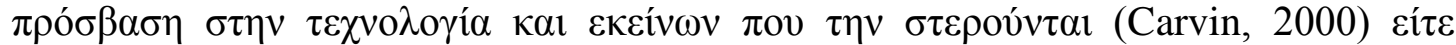

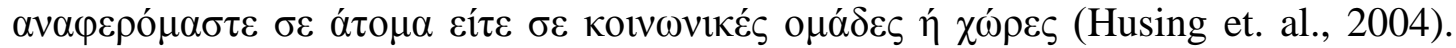

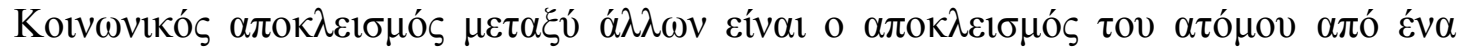

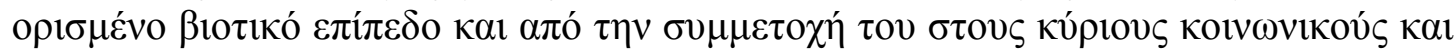

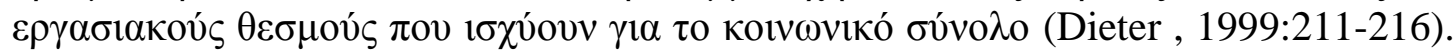

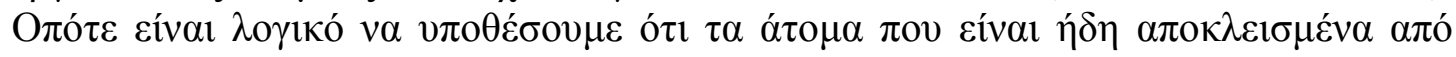

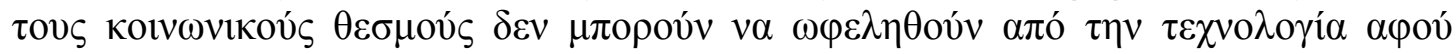

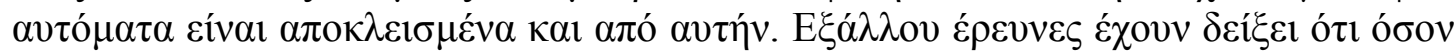

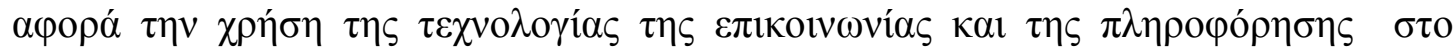

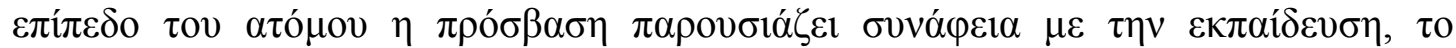

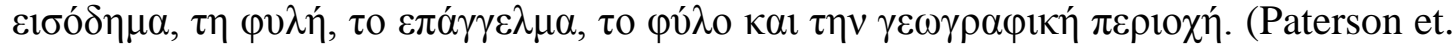

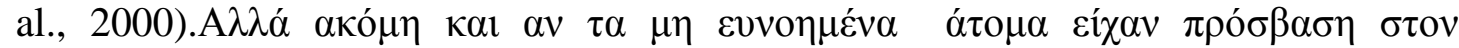

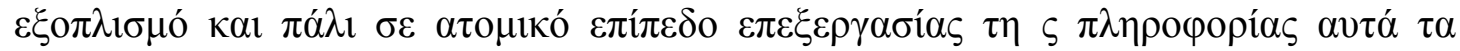

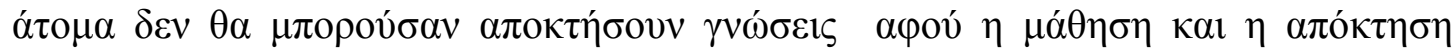

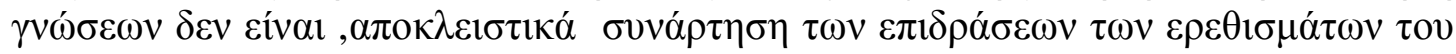

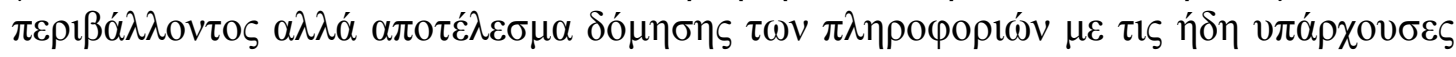

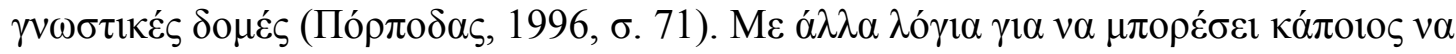

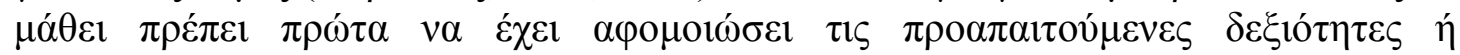

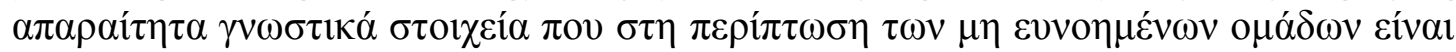

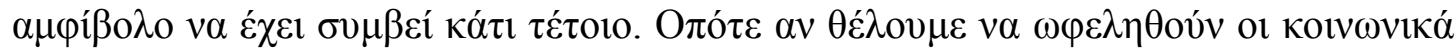

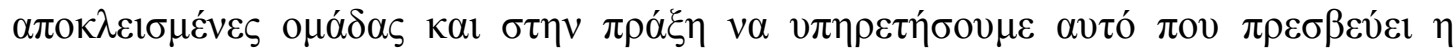

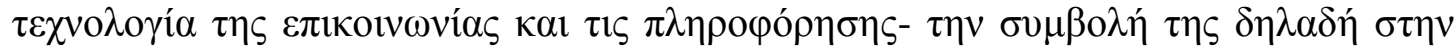

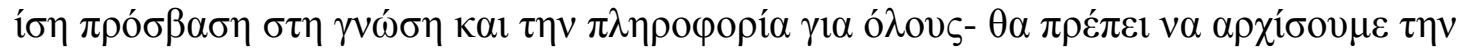

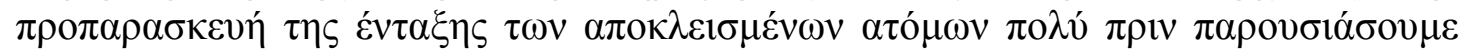

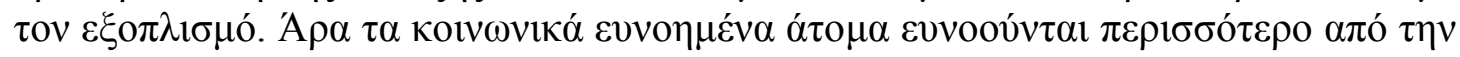

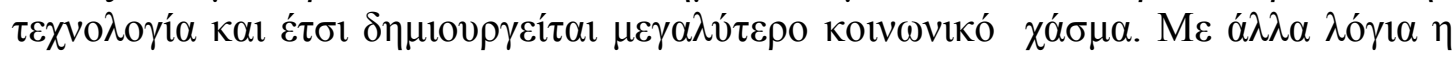

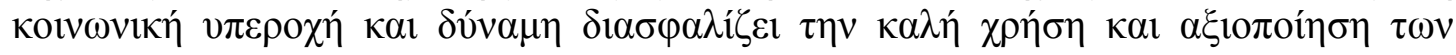

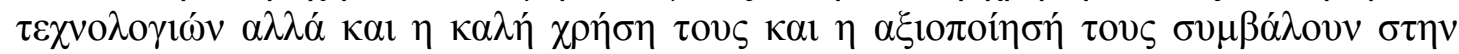

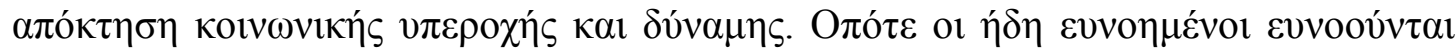

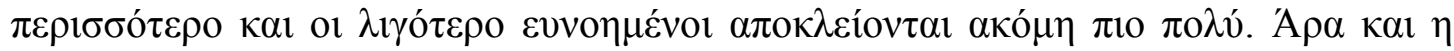

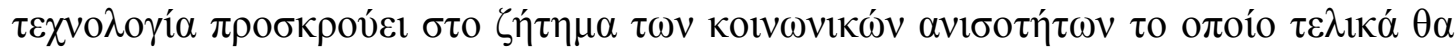

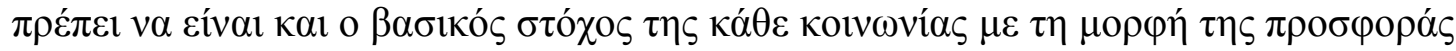

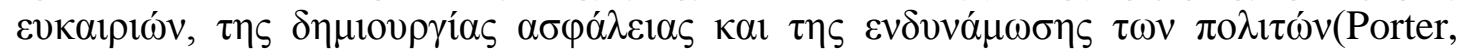

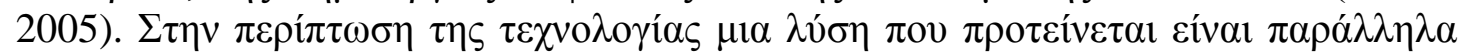

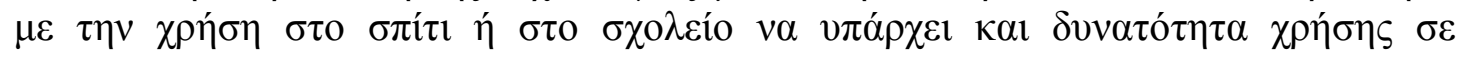

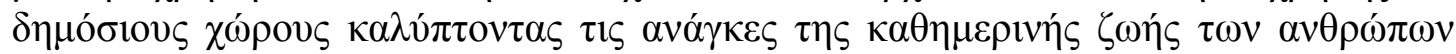

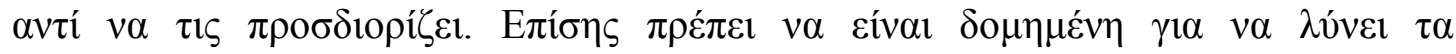

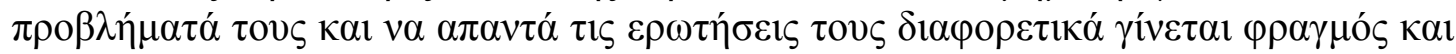

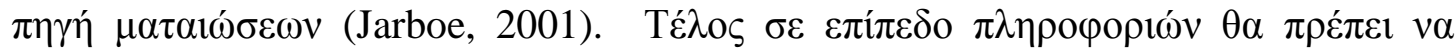

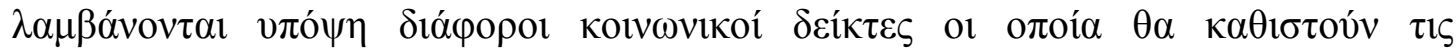

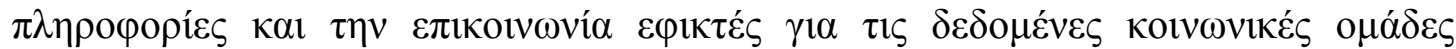

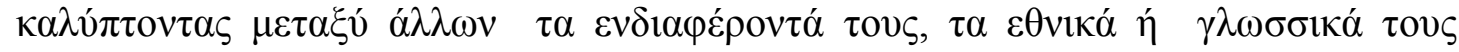




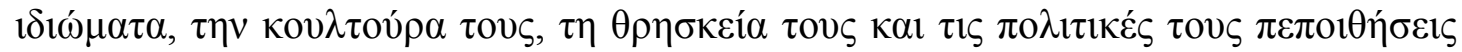
(Lievrouw, 2000).

\section{$\Sigma v \mu \pi \varepsilon ́ \rho \alpha \sigma \mu \alpha$}

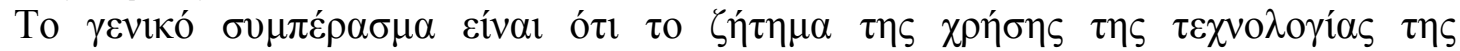

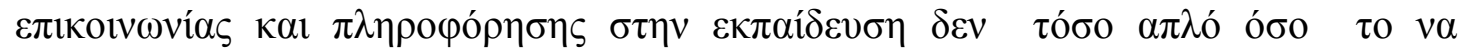

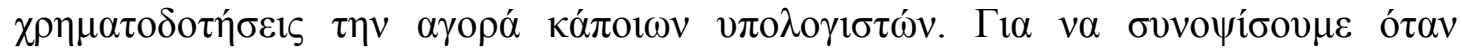

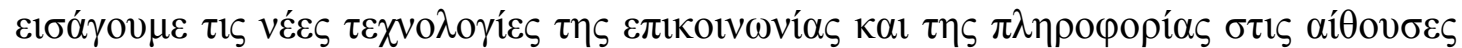

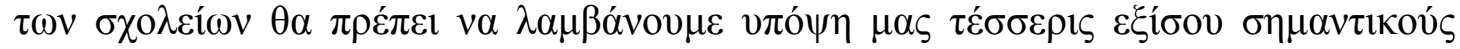

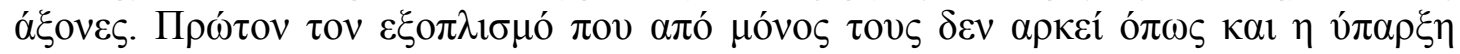

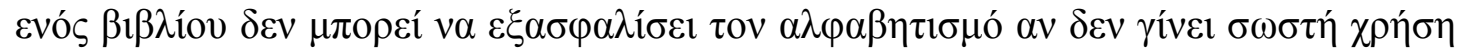

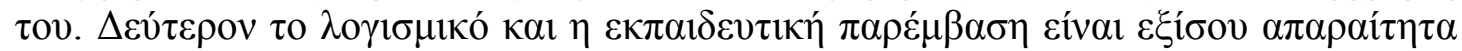

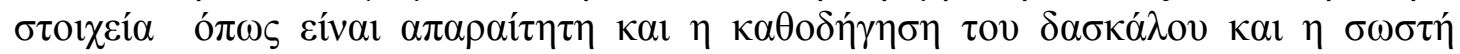

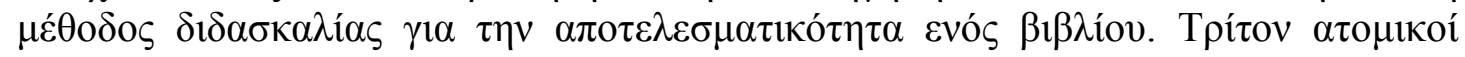

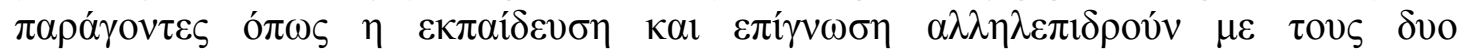

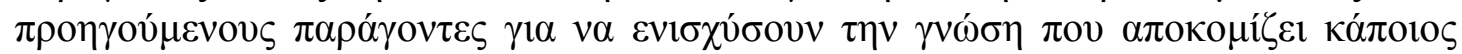

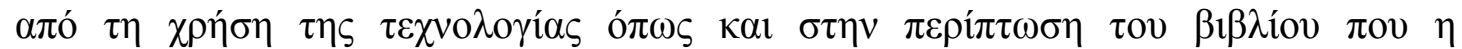

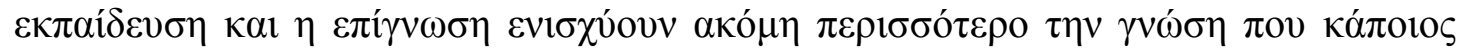

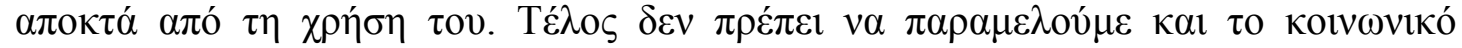

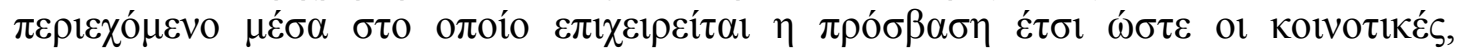

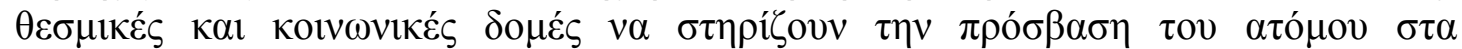

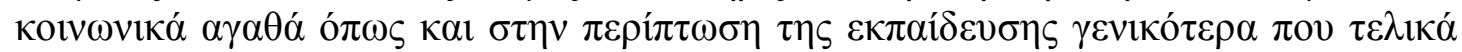

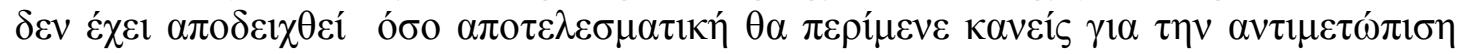

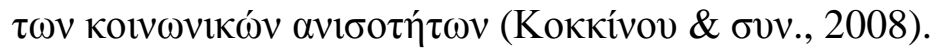

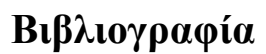

$\mathrm{E} \lambda \lambda \eta v \imath \kappa \eta ́$

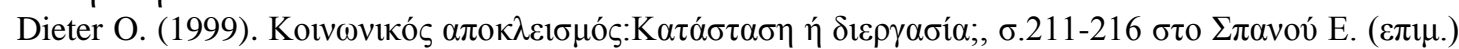

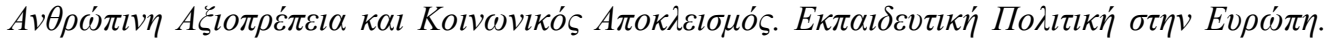

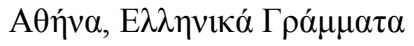

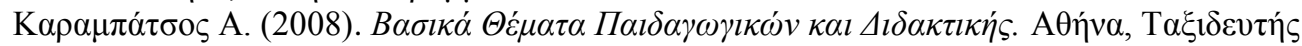

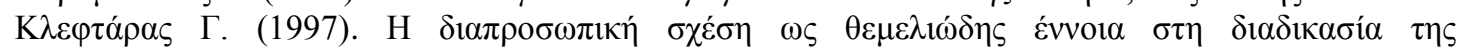

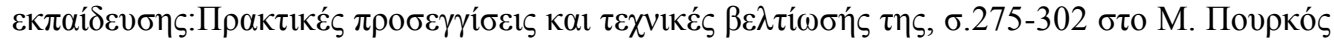

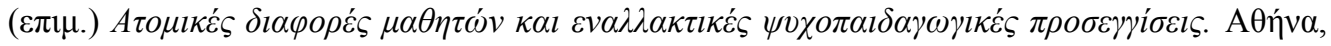
Gutenberg

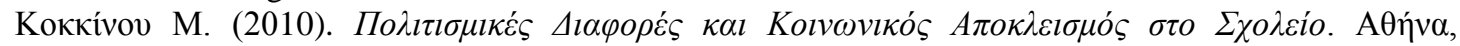

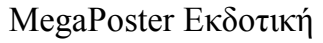

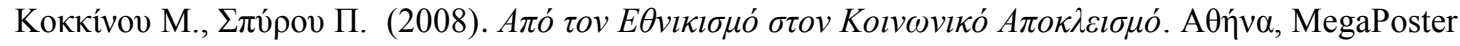

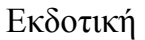

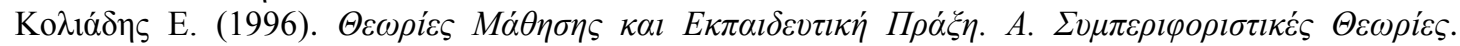
A $\theta \dot{v} v \alpha$, Ko $\lambda ı \alpha ́ \delta \eta \varsigma$

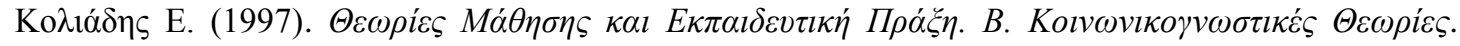

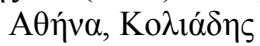

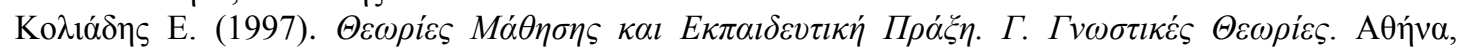

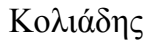

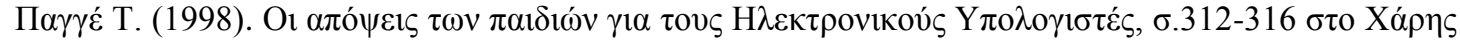

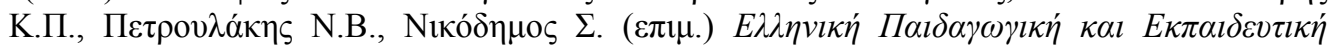

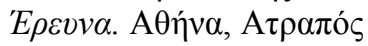

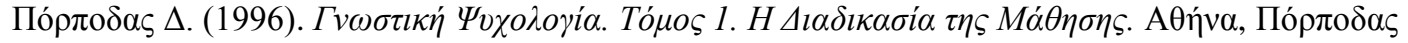

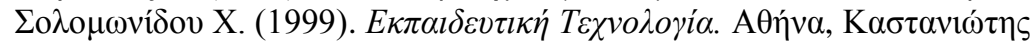

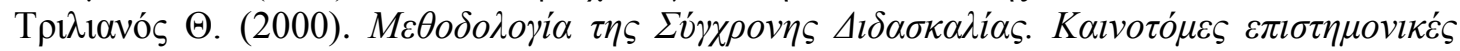

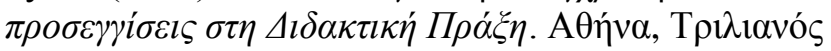

\section{$\Xi \varepsilon v o ́ \gamma \lambda \omega \sigma \sigma \eta$}


Carvin A. (2000). Mind the gap: The digital divide as the civil rights issue of the new millennium, Multimedia Schools 7(1) at http://www.infotoday.com/MMSchools

Dewey J. (1971). The Child and the Curriculum. The School and Society. Chicago-London, The University of Chicago Press

Freire P. (1970). The adult literacy process as cultural action for freedom, Harvard Educational Review, 40, pp. 205-212

Husing T.,Selhofer H. (2004). DIDIX:Digital Divide Intex for Meaasuring Inequality in IT Diffusion, IT\&SOCIETY 1(7), pp. 21-38

Jarboe K. (2001). Inclusion in the information age:Reframing the debate, Athena Alliance at http://www.athenaalliance.org/inclusion.html

Lievrouw L. (2000). The Information Environment and Universal Service, The Information Society 16, pp. $155-159$

Mitra S. (1999). Minimally invasive education for mass computer literacy, CSI Communications (June), pp. 12-16

Porter D. (2005). The third way and the third world: poverty reduction and social inclusion strategies in the rise of "inclusive" liberalism", Review of International Political Economy 12, pp. 226-263

Paterson R., Wilson E. (2000). New IT and Social Inequality:Resetting the Research and Policy Agenda, The Information Society 16, pp.77-86

Swazo N. (2005). Research integrity and rights of indigenous peoples:appropriating Foucault's critique of knowledge/power, Studies in History and Philosophy of Biological and Biomedical Science 36, pp. 568-584

U.S. Department of Commerce, Economic and Statistics Administration, National Telecommunications and Information Administration (2000). Falling Through the Net: Towards Digital Inclusion. Washington, DC: NTIA

Warschauer M. (2002). Reconceptualizing the Digital Divide, First Monday 7(7-1) at http://firstmonday.org/htbin/cgiwrap/bin/ojs/index.php/fm/article/viewArticle/967/888

\section{Sites}

http://www.eircom.ie

http://www.ennis.ie

http://www.castlebar.ie

http://www.kilkenny.ie

http://www.kerry.local.ie/killarney 